\title{
De las triangulaciones del Presidente, Corpesca y otros casos: Los peligros de la corrupción para Chile.
}

El reciente caso de las denuncias por triangulaciones de los fondos de inversiones con Aseguradoras de Fondos de Pensiones (AFP) y que involucrarían a la figura del Presidente de la República Sebastián Piñera, se suma ya a una larga lista de casos que durante los últimos años que engrosan un conjunto de acusaciones de sobre delitos de corrupción en las cuales se han visto involucrados una serie de autoridades políticas e instituciones del Estado.

Es más, recientemente a raíz del caso "Corpesca" y en un hecho inédito en la historia política y procesal de este país, se ha declarado en primera instancia la culpabilidad del ex senador Orpis y la ex diputada Isasi por delitos como cohecho y fraude al Fisco, en el contexto de la aprobado de la controvertida "Ley de Pesca" impulsada por el entonces Ex Ministro Pablo Longueira, el cual también ha enfrentado múltiples acusaciones de corrupción en los últimos años.

Ahora bien, no solamente es patrimonio exclusivo de la derecha política chilena su presunta relación con casos de corrupción, sino que en otros sectores políticos se vive situaciones similares, tal como es el caso del líder del partido Progresista Marco Enríquez- Ominami o los casos de corrupción que afectaron a la administración de la ex Presidenta Michelle Bachelet en su último mandato, tales como el caso Caval, muestran que el fenómeno de acusaciones y presuntos hechos de corrupción a nivel nacional, es algo transversal a las diversas coaliciones políticas.

Pero más preocupante aún, es el escenario en materia de las instituciones de la república, en especial en los casos de carabineros y el ejército que en los últimos años se han visto envueltos en bullados casos de desfalco a las arcas fiscales, lo cual ha mermado y ha sido el inicio de las graves crisis institucionales que actualmente viven, las cuales se vieron agudizadas por las acusaciones de violaciones a los derechos humanos efectuadas por miembros de estas organizaciones en el contexto del "estallido social" de octubre de 2019.

Todo lo anterior, es la muestra patente que desde los últimos años en nuestro país ha existido un fenómeno cada vez más común e inclusive hasta normalizado de que nuestros políticos e instituciones son más propensas que en antaño en caer en acciones reñidas con la ética y probidad pública, lo cual no solamente se refleja en las portadas de los medios de comunicación o en la apertura de procesos judiciales, sino que también ha impactado en la imagen de la ciudadanía sobre la institucionalidad vigente a nivel general. 
Es más, los resultados de un estudio efectuado en noviembre del presente año, por la Contraloría General de la República, en relación con la percepción de los ciudadanos sobre la corrupción en Chile, han dejado una serie de repercusiones y que principalmente se traducen en que los ciudadanos piensan que existe una mayor ocurrencia de acciones que se riñen con la ética pública.

Lizcano y Mendieta (2011), manifiestan que la mayor problemática para el Estado democrático y de derecho no es solamente este fenómeno, sino que a la par se produce un deterioro de la moral y ética pública, que tiene como a sus principales sujetos a los funcionarios públicos.

En el caso chileno, la ocurrencia de una creciente práctica de corrupción, puede ser nocivo para el país, más aún en este momento en particular, el cual se caracteriza por una nación que enfrenta las consecuencias económicas de la pandemia del COVID-19, con la figura de un presidente y un gobierno que enfrentan desde hace más de un año una fuerte crisis de conducción, un proceso constante de movilización social desde el 18-O, con una clase política transversalmente desprestigiada ante los ojos de la ciudadanía y ad portas de un proceso constitucional, que hasta el minuto tiene más incertidumbres que certezas. El escenario descrito, puede generar en conjunto las condiciones de debilitamiento de la estabilidad democrática e institucional, que en el peor de los casos podría significar un retroceso a la realidad política latinoamericana de los años 70's y 80's del siglo pasado o al surgimiento de populismos de cualquier signo, que sin duda debilitarían aún más nuestra institucionalidad.

En este sentido, la ciudadanía tiene como conjunto que exigir a sus autoridades políticas y jurisdiccionales, el respeto a la institucionalidad vigente y el pleno derecho a los distintos caminos dentro de la legalidad existente a resguardar el respeto de los valores de la ética pública, tomando posiciones no solamente pasiva de solicitud del respeto de los mismo, sino que también convertirse en actores activos y los primeros fiscalizadores de la gestión estatal, mediante un proceso de empoderamiento y observación del devenir de la administración pública a nivel nacional.

Dichas autoridades, en post del resguardo de la institucionalidad vigente y de velar por un sano clima de convivencia política nacional, deben manifestar mediante acciones concretas como la implementación de políticas que fortalezcan el rol de los organismos fiscalizadores a nivel nacional y de las sanciones administrativas, penales y civiles en la materia, con tal de generar las condiciones necesarias para reducir la ocurrencia de este tipo de acciones reñidas con la legalidad.

Por último, también es rol de estas instituciones como la Contraloría General de la República e inclusive el poder judicial, actuar con la acuciosidad, eficacia y eficiencia en post de resolver las controversias asociadas a estas materias, en virtud de los efectos importantes que tienen para la vida en sociedad.

En síntesis, para finalizar es menester indicar que Chile se enfrenta el peligro latente de la corrupción y es tarea de todos colaborar en vencer a este mal endémico, en post del resguardo del fortalecimiento institucional de nuestro sistema democrático y más importante aún para reestablecer desde el mundo político y la gestión pública, las confianzas entre el Estado y las personas. 
Por Diego Durán Toledo, Administrador Público y Magíster en Gobierno y Gerencia Pública. Académico e Investigador de la Universidad Autónoma de Chile. 